\title{
Theoretical Study of the Reactivity of Phenyl Radicals Toward Enol Acetates
}

\author{
Leonardo S. A. Carneiro, ${ }^{\oplus a}$ Leticia H. S. P. C. Real, ${ }^{\oplus b}{ }^{b}$ Camilla D. Buarque ${ }^{\oplus * a}$ and \\ Pierre M. Esteves ${ }^{\circledR *}$ *c \\ ${ }^{a}$ Departamento de Química, Pontifícia Universidade Católica do Rio de Janeiro (PUC-Rio), \\ Rua Marquês de São Vicente, 225, Gávea, 20551-031 Rio de Janeiro-RJ, Brazil \\ ${ }^{b}$ Department of Chemistry \& Biochemistry, University of Oklahoma, 101 Stephenson Parkway, \\ 73019 Norman, Oklahoma, United States \\ 'Instituto de Química, Universidade Federal do Rio de Janeiro (UFRJ), Av. Athos da Silveira Ramos, \\ 149, CT, Bloco A-622, Cidade Universitária, Ilha do Fundão, 21941-909 Rio de Janeiro-RJ, Brazil
}

\begin{abstract}
Arylation reactions are an important class of reactions and allow the synthesis of natural and synthetic products. Despite the efficient, but high cost and toxic methodologies involving transition metals, radical arylations have gained importance after the advent of photoredox catalysis. Arylation of enol acetates is an important tool for obtaining aryl ketones but the scope of the reaction is limited to the pattern of substitution at phenyl radical and $\alpha$-carbon of the enol. Theoretical calculations ((U)BHandHLYP/6-311G**) show that the polar effect is the key factor in this reaction. A good correlation of calculated rate constants with field effect explained why phenyl radicals with electronwithdrawing groups react faster toward enol acetate. The presence of alkyl groups at $\alpha$ carbon at the enol showed some influence of enthalpic effect but strong influence of steric effect, evidenced by great correlations with Taft and Charton parameters. Finally, substitution at $\beta$ carbon showed no significant effect at reaction rates.
\end{abstract}

Keywords: Meerwein arylation, phenyl radicals, enol acetate, field effect

\section{Introduction}

The insertion of aryl groups in organic scaffolds is an important class of reaction in Organic Chemistry. Despite metal-catalyzed arylation reactions being the most studied cases, with new methodologies being reported every year, ${ }^{1-4}$ since the advent of photoredox catalysis the generation of aryl radicals gained prominence due to the use of mild reaction conditions, readily available radical precursors (e.g., diazonium salts, hypervalent iodonium species, sulfonyl chlorides, and aryl halides) and the possibility of metal-free methodologies through the use of organic dyes as photocatalysts. ${ }^{5,6}$

The Meerwein arylation was introduced in 1939 as a methodology to promote arylations of alkenes using diazonium salts catalyzed by $\mathrm{Cu}$ (II) salt in a buffer media. ${ }^{7}$ Meerwein et al. ${ }^{7}$ proposed that a phenyl cation is formed through cleavage of $\mathrm{Ar}-\mathrm{N}_{2}{ }^{+}$bond. Later, some works proposed the formation of a phenyl radical

*e-mail: camilla-buarque@puc-rio.br; pesteves@iq.ufrj.br instead of that cation. ${ }^{8-11}$ This idea was further used by König and co-workers ${ }^{12}$ to develop photoredox arylation methodologies. A large variety of substrates can be arylated using phenyl radicals (Figure 1a), such as alkenes, alkynes, enones, heterocycles, isonitriles, and cinnamic acids. ${ }^{13}$ The photoredox version of the Meerwein arylation was developed in 2012 and allowed the formation of $\mathrm{C}-\mathrm{C}$ bonds in alkenes, alkynes, heteroarenes, and enones with reasonable yields. ${ }^{12}$ After this contribution, the same group showed that $\alpha$-arylations of ketones could be achieved when enol acetates are submitted to photoredox conditions in the presence of diazonium salts (Figure 1b) ${ }^{14}$ Typically these reactions require harsh conditions and expensive catalysts, so it was an important breakthrough for the $\alpha$-functionalization of carbonyl compounds.

The visible-light excitation of the photocatalyst allows the formation of aryl radicals via single electron transfer (SET) reactions. ${ }^{5}$ The proposed mechanism ${ }^{14}$ (Figure 2) shows that after the formation of the phenyl radical, it is added to the enol acetate generating a radical adduct. This species can donate an electron to the photocatalyst or to 
(a)

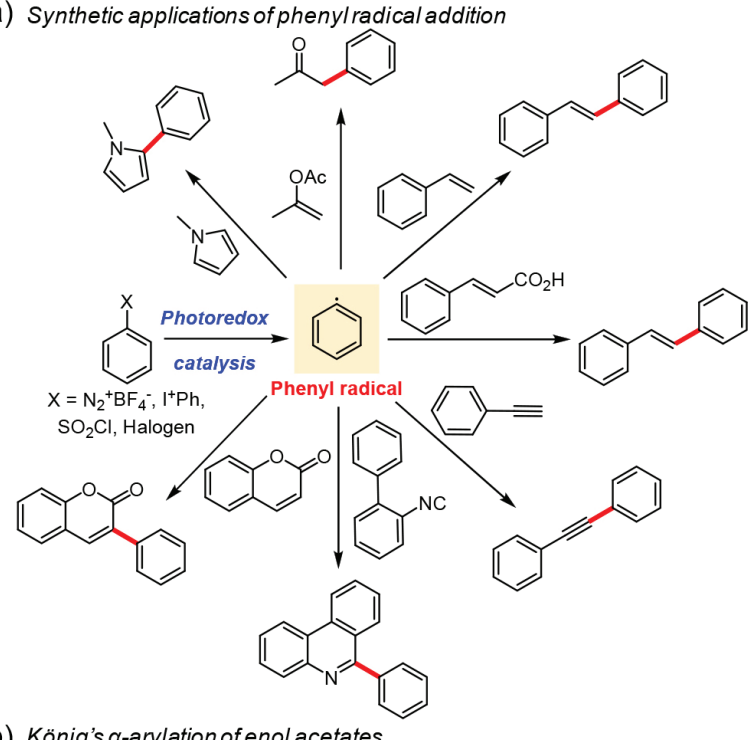

(b) König's $\alpha$-arylation of enol acetates

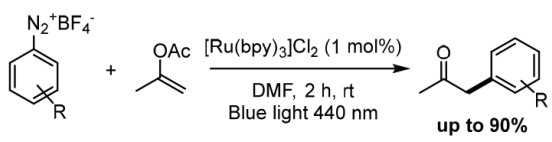

Figure 1. (a) Representative arylation reactions induced by visible light. (b) Photoredox arylation of enol acetates with diazonium salts.

another diazonium salt (chain propagation) generating a cationic species, which undergo elimination to provide the desired product. Substituent groups at König's arylation seem to influence the reaction yields. Electron-withdrawing groups at diazonium salts afford the best yields, while electron-donating groups result in moderate yields. The authors try to explain these findings supporting their arguments on the redox potentials of the $\mathrm{ArN}_{2}{ }^{+}$. Diazonium salts containing electron-withdrawing substituents have lower reduction potentials, being "easier" to be reduced to

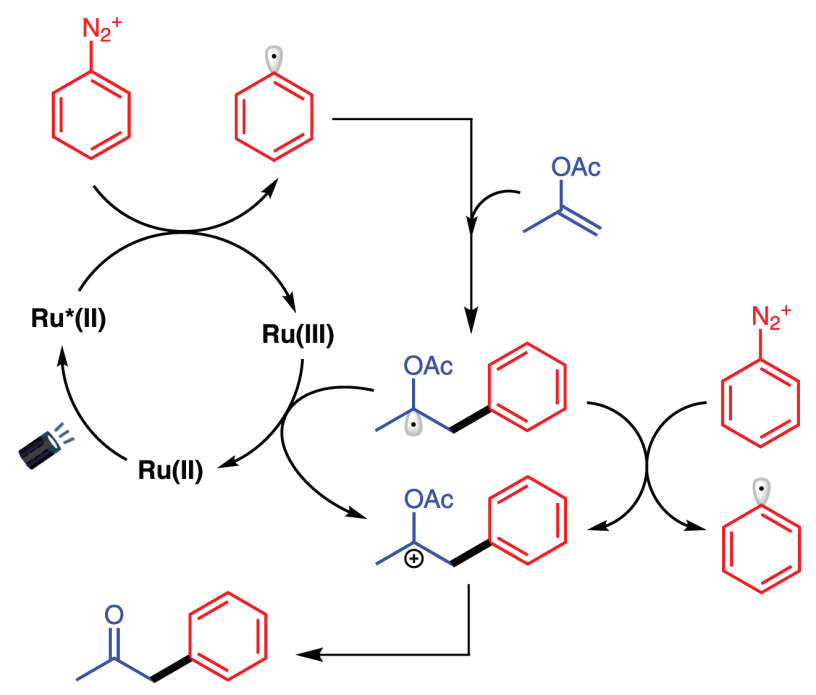

Figure 2. General proposed catalytic cycle for phenyl radical addition to enol acetate. ${ }^{5}$ the phenyl radicals. Later, de Oliveira and co-workers ${ }^{15}$ used porphyrines combined with continuous flow setup to run the same reactions, observing a similar trend on reactivity.

Conversely to the general belief, one could alternatively interpret those results as the following: once the radical is formed, the aryl radical addition step dictates the reactivity, i.e., the radical addition to the unsaturated compound is the rate-determining step, as previously reported. ${ }^{16-18}$ Some reports of photoredox methodologies show the same tendency. ${ }^{16,17}$ Kinetic isotope effect experiments conducted by Yoon and co-workers ${ }^{19}$ confirmed that $\alpha$-amino radical addition to methyl vinyl ketone in the absence of Brønsted acid is rate-determining. The formation of radicals at photoredox catalysis can be close to a diffusionalcontrolled limit. ${ }^{19,20}$ Deronzier and co-workers ${ }^{21}$ showed that quenching of $\left[\mathrm{Ru}(\mathrm{bpy})_{3}\right]^{2+}$ (where bpy is 2,2 '-bipyridine) by benzenediazonium tetrafluoroborate as an electron transfer process is $3.4 \pm(0.2) \times 10^{9} \mathrm{M}^{-1} \mathrm{~s}^{-1}$ in acetonitrile, suggesting that diazonium salt quenches the photocatalyst in a very fast process. These facts are in contrast with König's assumption that reactivity of arylation of enol acetates is dictated by the redox potential of the diazonium salts and, conversely, the reduction step would be the rate-determining step. ${ }^{14}$

Phenyl radicals can either promote hydrogen atom abstractions or additions to $\pi$-systems, with the latter tending to be faster. Bevington and $\mathrm{Ito}^{22}$ showed that addition to styrene is almost 12 to 20 times faster than hydrogen abstraction to styrene and methyl methacrylate. Kosugi and co-workers ${ }^{23}$ observed that $p$-nitrophenyl radicals add 10.7 times faster to allyl methyl sulfide and 15.4 times faster to allyl phenyl sulfide. Scaiano and Stewart ${ }^{24}$ showed that addition to styrene, $\beta$-methylstyrene, and methyl acrylate are fast processes, with rate constants $(\mathrm{k})$ ranging from $10^{7}$ to $10^{8} \mathrm{M}^{-1} \mathrm{~s}^{-1}$. Preidel and Zellner ${ }^{25}$ found slower additions with ethylene, but-2-ene and acetylene $\left(\mathrm{k}=1.2 \times 10^{4}, 1.6 \times 10^{4}\right.$ and $4.8 \times 10^{5} \mathrm{M}^{-1} \mathrm{~s}^{-1}$, respectively). Vismara and co-workers ${ }^{26}$ pointed that reaction of $p$-chlorophenyl radicals to $\alpha, \beta$-unsaturated carbonyl compounds prefer the addition to $\alpha$-carbon with rate constants ranging from $1.77 \times 10^{7}$ to $1.33 \times 10^{8} \mathrm{M}^{-1} \mathrm{~s}^{-1}$. Density functional theory (DFT) analysis of the addition of phenyl radical to methyl acrylate revealed that phenyl radical had no remarkable nucleophilic or electrophilic character. ${ }^{27}$ Few reports studied non-activated alkenes. Zhao and coworkers ${ }^{28}$ estimated that the addition of $p$-chlorophenyl radical to vinyl acetate has $\mathrm{k}=2.7 \times 10^{6} \mathrm{M}^{-1} \mathrm{~s}^{-1}$. Kirschstein and co-workers ${ }^{29}$ showed that phenyl radical addition to allyl acetate is 10 times slower than its addition to ethyl acrylate. ${ }^{30}$ Unfortunately, on the best of our knowledge, no kinetic data are available for the addition of radicals to enol acetates, which can be obtained from the parent ketones. 
Many studies ${ }^{20-26,30,31}$ discussed the mechanism of carbon-centered radicals to alkenes. Tedder ${ }^{32-35}$ and Giese ${ }^{36}$ proposed that three main factors regulate these reactions: steric, enthalpic and polar effects. The steric effect is related to the increase in energy barrier with substitutions at alkene, lowering the rate constants. ${ }^{37}$ The so-called "enthalpic effect" dictates how structural modifications, in terms of exothermicity, affects the activation barrier, correlating like Evans-Polanyi-Semenov relation. ${ }^{38-40}$ Finally, the polar effect describes the influence of substituents at radical and alkene on their frontier molecular orbitals (FMO) ${ }^{41,42}$ Due to the lack of consensus about the mechanism photoredox version of the Meerwein arylation, the present contribution aims to investigate the radical addition to enol acetates, using DFT calculations, to elucidate the role of substitutions in the reactivity.

\section{Results and Discussion}

The observation of the substituent effects on the reaction kinetics can be interpreted as how the two carbon atoms of the double bonds in the enol acetate are electronically demanded on the rate-controlling transition state (Scheme 1).

The change of substituent $\mathrm{R}^{1}$ monitors the sensitivity of the reaction mainly at carbon $\mathrm{C}_{\alpha}$ while $\mathrm{C}_{\beta}$ can be more directly evaluated by varying substituents $\mathrm{R}^{2}$ and $\mathrm{R}^{3}$. This work was divided into three approaches, each one aiming to understand the influence of these substituents on the reaction kinetics. In the first approach, the role of substituents $\mathrm{R}^{1}$ at para-substituted phenyl radicals attacking the enol acetate derived from acetone $\left(R^{2}=H\right.$ and $\mathrm{R}^{3}=\mathrm{Me}$ ) was investigated. In a second approach, the influence of alkyl groups at $\alpha$-carbon of the enol acetate on its reaction with the $p$-nitrophenyl radicals was investigated (influence of $\mathrm{R}^{2}$ ). Finally, the third approach analyzes the role of substituents on different acetophenones reacting with $p$-nitrophenyl radicals $\left(\mathrm{R}^{3}\right)$. These calculations will allow a better comprehension of the electronic demand on both carbons of the $\mathrm{C}=\mathrm{C}$ of the enol acetate. The choice of these systems is related to the main factors that affect radical additions to alkenes: enthalpic, polar, and steric effects.
The UBHandHLYP/6-311G** level of theory was chosen to describe our systems. ${ }^{43}$ This level is often employed in reactions involving organic radical studies successfully. ${ }^{4-46}$ The geometries were fully optimized for reactants (substituted radical intermediate and enol acetates), the transition state (TS) for the addition at $\alpha$-carbon, as well as the corresponding adducts. Vibrational analysis at the optimized geometries confirmed that the structures correspond to minima at the potential energy surface (PES), by the absence of imaginary frequencies. On the other hand, first-order transition states were characterized by the existence of a single imaginary frequency, which, when animated indicates the expected reaction coordinates. Additionally, the intrinsic reaction coordinate (IRC) calculations were carried out to confirm that the transition state connects the expected reactants to the products of this elementary step. At the optimized geometries of the TS, single-point energy calculations were carried out to perform natural bond order $(\mathrm{NBO}),{ }^{47}$ charge variation to the reactants, and FMO analysis. This will allow one to evaluate how the structural parameters are influencing the reaction rate.

Figure 3 shows a typical transition state for the addition of the phenyl radical to the enol acetate, with selected geometric parameters. The angle of approximation $\left(107.2^{\circ}\right)$ of the reactants at the TS follows the geometry proposed by Bürgi et al..$^{48}$ and by the distance $\mathrm{r}_{\mathrm{CC}}$ of about $2.4 \AA$ indicates an early TS. The reaction is exergonic, which was found for all cases. This means that the substituent effects at TS should be more alike to the ones in reactants than to the products, according to the Hammond postulate. ${ }^{49}$

Aiming to investigate the influence of polar and enthalpic effects, the transition states bearing different groups at the para position of phenyl radical were optimized, as well as the reactants. This allowed calculating the TS Gibbs free energy $\left(\Delta \mathrm{G}^{\ddagger}\right)$ and enthalpy $\left(\Delta \mathrm{H}^{\ddagger}\right)$, the reaction Gibbs free energy $\left(\Delta \mathrm{G}_{\mathrm{rxn}}\right)$ and enthalpy $\left(\Delta \mathrm{H}_{\mathrm{rxn}}\right)$, shown in Table 1. All phenyl radical additions are exothermic with $\Delta \mathrm{H}_{\mathrm{rxn}}$ ranging from -37.3 to $-40.0 \mathrm{kcal} \mathrm{mol}^{-1}$. They are all exergonic with $\Delta \mathrm{G}_{\mathrm{rxn}}$ varying from -25.0 to $-26.7 \mathrm{kcal} \mathrm{mol}^{-1}$. The analysis of thermodynamic quantities for TS showed small activation barriers, which is consistent with the early TS

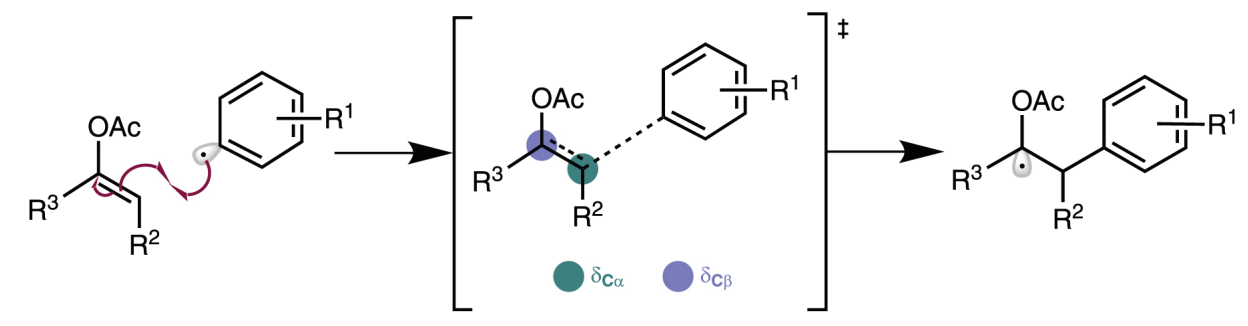

Scheme 1. Phenyl radical addition to enol acetates mechanism. 


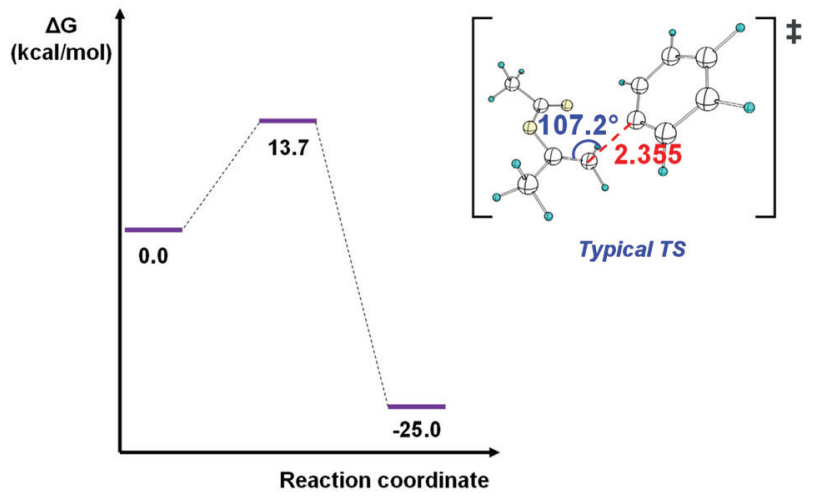

Figure 3. Energy profile diagram calculated at UBHandHLYP/6-311G** level of theory. The approximation distance is expressed in angstroms $(\AA)$.

found by IRC calculation and supported by Hammond's postulate. ${ }^{49}$ Electron-withdrawing substituents decrease the energy barrier, although there is a poor correlation between this quantity and the reaction enthalpy.

Figure 4a presents the Arrhenius activation energy, calculated from $E_{a}=\Delta H^{\ddagger}+R T$ (where $R$ is the gas constant and $\mathrm{T}$ is the temperature), as a function of $\Delta \mathrm{H}_{\mathrm{rxx}}$, which may be related to the position of the transition state along the reaction coordinate $(\alpha)$ within the Evans-Polanyi principle framework. A poor correlation $\left(\mathrm{r}^{2}=0.743\right)$ is found with a slope of $\alpha=0.375$, which being less than 0.5 , indicates an early TS, considering that $0 \leq \alpha \leq 1 .^{50}$ This shows that, although the enthalpic effect has some influence on the reaction rate, the exothermicity of the reaction has only a small effect on the activation energy for the present case. Fouassier and co-workers ${ }^{27}$ showed that the alkyl radicals addition to the methyl acrylate double bond has a strong influence on the enthalpic factor. In the same work, however, it was observed that the aminoalkyl and the dialkylketyl radicals also present poor correlation. These cases were studied by the same authors and the polar effects were pointed as the driving force to such reaction. ${ }^{51}$ It induced this work to investigate how the polar effects induce the observed reactivity. The radical singly occupied molecular orbital (SOMO energies, Table S1, Supplementary Information (SI) section) were calculated in the framework of the molecular orbital (MO) theory using the Hartree-Fock part of the UMP2/6-31G** level of theory calculation. The energies correlate well with $\Delta \mathrm{G}^{*}$ $\left(r^{2}=0.890\right.$, Figure $\left.4 b\right)$. As the SOMO energy becomes more negative, the reaction barrier becomes lower, meaning that a more electrophilic aryl radical is beneficial for the reaction rate. This also suggests that the enol acetate is serving as a nucleophile and the radical seems to be playing the electrophile role in this reaction.

The Klopman-Salem equation ${ }^{52,53}$ describes the change of total energy involved in the process of approaching of two chemical species, in terms of their individual overlapping molecular orbitals, based on a Taylor expansion of the total energy (perturbation theory). The third term of this equation is the second-order perturbation, which comes from the interaction between filled/unfilled orbitals. In terms of the desired reaction, the second-order perturbation is related to $\mathrm{SOMO}-\mathrm{HOMO}_{\text {enol }}$ (HOMO: highest occupied molecular orbital) and SOMO-LUMO enol $_{\text {(LUMO: lowest unoccupied }}$ molecular orbital) interactions. Mathematically, two

Table 1. Calculated transition state Gibbs free energy $\left(\Delta \mathrm{G}^{\ddagger}\right)$ and enthalpy $\left(\Delta \mathrm{H}^{\ddagger}\right)$, reaction Gibbs free energy $\left(\Delta \mathrm{G}_{\mathrm{rxn}}\right)$ and enthalpy $\left(\Delta \mathrm{H}_{\mathrm{rxn}}\right)$ at $\mathrm{UBHandHLYP/6}$ $311 \mathrm{G}^{* *}$ level of theory

\begin{tabular}{|c|c|c|c|c|}
\hline $\mathrm{R}^{1}$ & $\Delta \mathrm{G}^{\ddagger} /\left(\mathrm{kcal} \mathrm{mol}^{-1}\right)$ & $\Delta \mathrm{H}^{\ddagger} /\left(\mathrm{kcal} \mathrm{mol}^{-1}\right)$ & $\Delta \mathrm{G}_{\mathrm{rxn}} /\left(\mathrm{kcal} \mathrm{mol}^{-1}\right)$ & $\Delta \mathrm{H}_{\mathrm{rxn}} /\left(\mathrm{kcal} \mathrm{mol}^{-1}\right)$ \\
\hline $\mathrm{H}$ & 13.7 & 2.3 & -25.0 & -37.3 \\
\hline $\mathrm{OMe}$ & 12.9 & 0.7 & -26.4 & -40.0 \\
\hline $\mathrm{Me}$ & 13.8 & 2.8 & -25.3 & -37.6 \\
\hline${ }^{t} \mathrm{Bu}$ & 13.7 & 2.8 & -25.5 & -37.7 \\
\hline $\mathrm{SiMe}_{3}$ & 13.6 & 2.8 & -25.1 & -37.3 \\
\hline $\mathrm{F}$ & 13.1 & 2.1 & -25.6 & -38.9 \\
\hline $\mathrm{Cl}$ & 13.0 & 1.9 & -25.9 & -38.2 \\
\hline $\mathrm{Br}$ & 13.0 & 2.0 & -26.7 & -38.9 \\
\hline $\mathrm{CF}_{3}$ & 12.5 & 2.6 & -25.8 & -38.1 \\
\hline $\mathrm{CN}$ & 12.3 & 2.4 & -26.3 & -37.6 \\
\hline $\mathrm{NO}_{2}$ & 12.0 & 2.2 & -26.3 & -38.6 \\
\hline
\end{tabular}



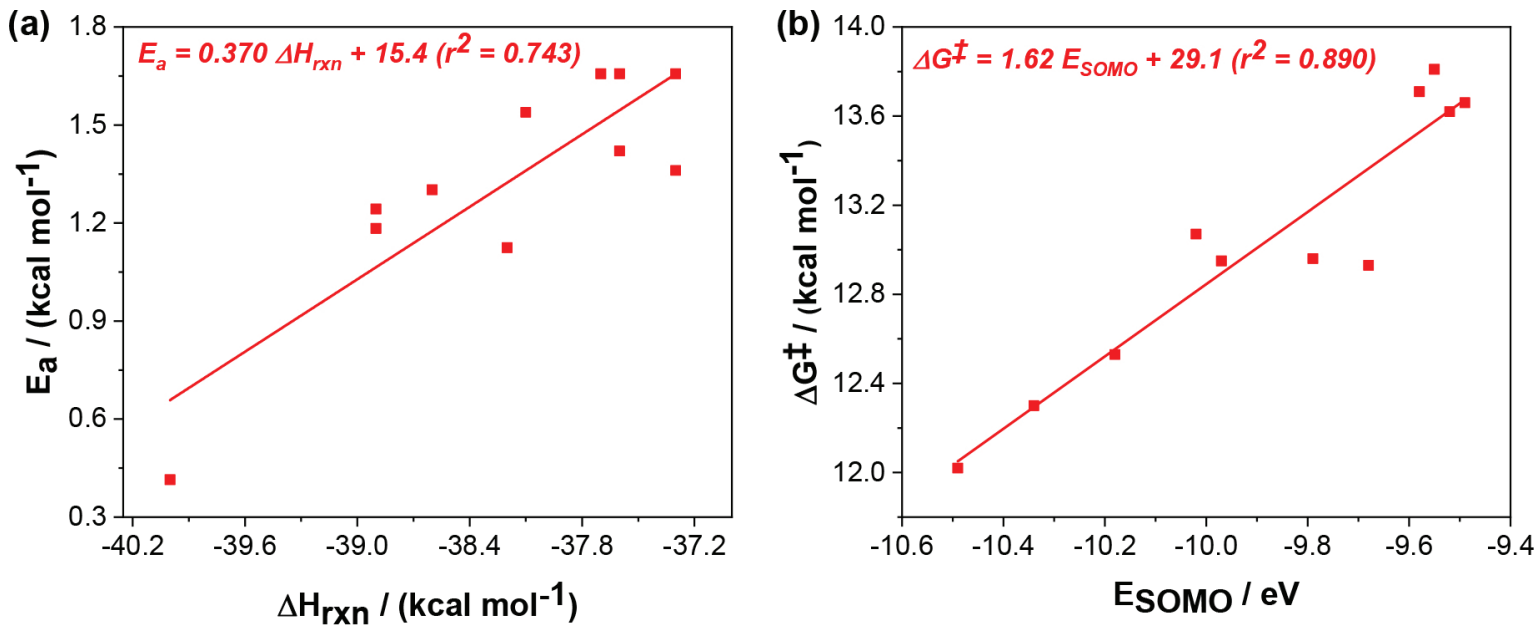

Figure 4. Plots of (a) activation barrier $\left(\mathrm{E}_{\mathrm{a}}\right)$ against reaction enthalpy $\left(\Delta \mathrm{H}_{\mathrm{rxn}}\right)$ and (b) SOMO energy against $\Delta \mathrm{G}^{\ddagger}$.

orbitals closer in energy contribute more to the interaction energy. From this perspective, the HOMO level of enol acetate $\left([\mathrm{HOMO}]_{\text {enol }}\right)$ is closer to the SOMO of the radical $\left([\mathrm{SOMO}]_{\text {Rad }}\right.$ ) than does the LUMO (Figure 5a). It points out that enol acetate acts as the nucleophile and phenyl radical as the electrophile. Natural bond orbital (NBO) analysis (Figure 5b), carried out using the Hartree-Fock part of the UMP2/6-31G** level of theory, reveals the same kind of interactions: $\mathrm{SOMO} \rightarrow \pi_{\mathrm{C}=\mathrm{C}}^{*}$ at $\alpha$ spin-set and $\pi_{\mathrm{C}=\mathrm{C}} \rightarrow \mathrm{SOMO}$ at $\beta$ spin-set. The stabilization contribution to the energies of the SOMO $\rightarrow \pi_{\mathrm{C}=\mathrm{C}}^{*}$ was calculated to be $21.3 \mathrm{kcal} \mathrm{mol}^{-1}$ and the $\pi_{\mathrm{C}=\mathrm{C}} \rightarrow$ SOMO is $29.1 \mathrm{kcal} \mathrm{mol}^{-1}$. This analysis confirms that the main contribution comes from the interaction $\pi_{\mathrm{C}=\mathrm{C}} \rightarrow \mathrm{SOMO}$, i.e., an electrophilic aryl radical attacking the nucleophilic enol acetate.

According to the intrinsic reaction coordinate (IRC) calculations (see Figure S1, SI section), the phenyl radical addition to enol acetate is an early TS. Based on
Hammond's postulate, ${ }^{49}$ this kind of TS is expected to be reactant-like, which means that stabilizing changes in the starting materials would also have a similar effect on the TS. Free energy relationships (LFER) establish the extent to which bond formation and bond breakage happen in the transition state of a reaction. Thus, these are a good way of evaluating the rate-determining transition state and how several structural effects affect it.

From the values of the reaction barriers $\left(\Delta \mathrm{G}^{\ddagger}\right)$, it is possible to derive $\log \mathrm{k}_{\mathrm{rel}}\left(\right.$ where $\left.\mathrm{k}_{\mathrm{rel}}=\mathrm{k}_{\mathrm{R} 1} / \mathrm{k}_{\mathrm{H}}\right)$, once they are formally linearly related (see the rationale at SI). Thus, with these values, correlations with the experimentally derived Hammett parameters $\left(\sigma_{\mathrm{p}}\right)$ and other LFER related quantities in the traditional way are possible. A correlation of $\log \mathrm{k}_{\mathrm{rel}}$ with $\sigma_{\mathrm{p}}$ constants was observed $\left(\mathrm{r}^{2}=0.753\right)$ (Figure 6a). No acceptable correlations were obtained either with $\sigma_{p}{ }^{+}$ and, surprisingly, with $\sigma^{*}$ (Creary scale, ${ }^{54}$ Figure S2, SI section). Swain and Lupton ${ }^{55}$ proposed that substituents' (a) MO diagram

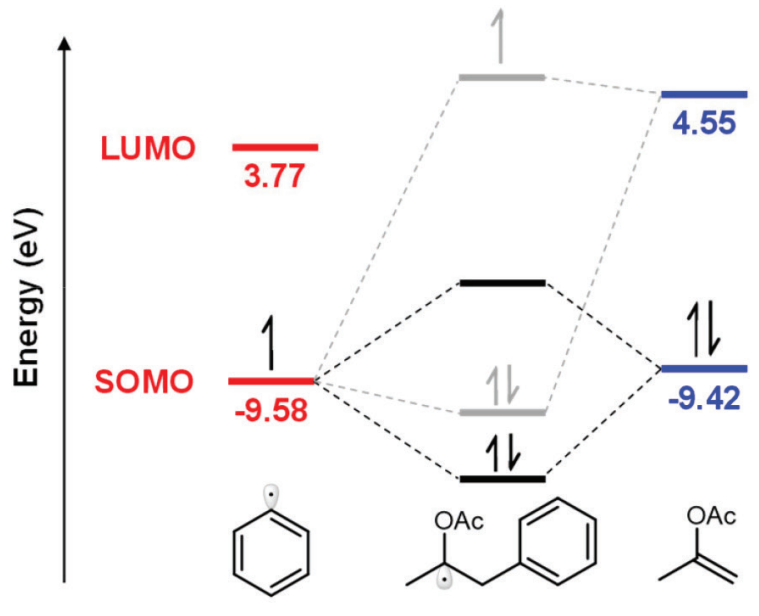

(b) NBO analysis

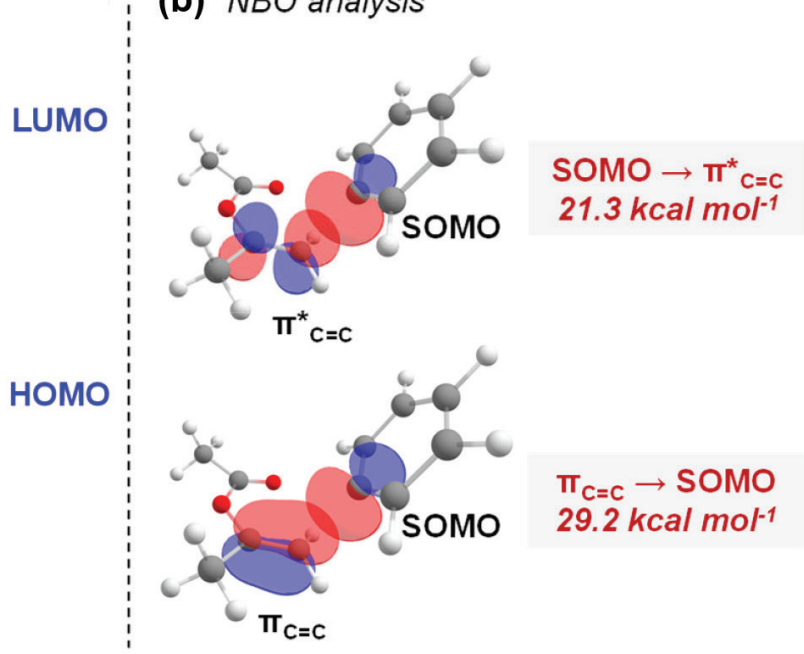

Figure 5. (a) Frontier molecular orbital diagram describing the possible MO interactions; (b) NBO involved at phenyl radical addition TS. 

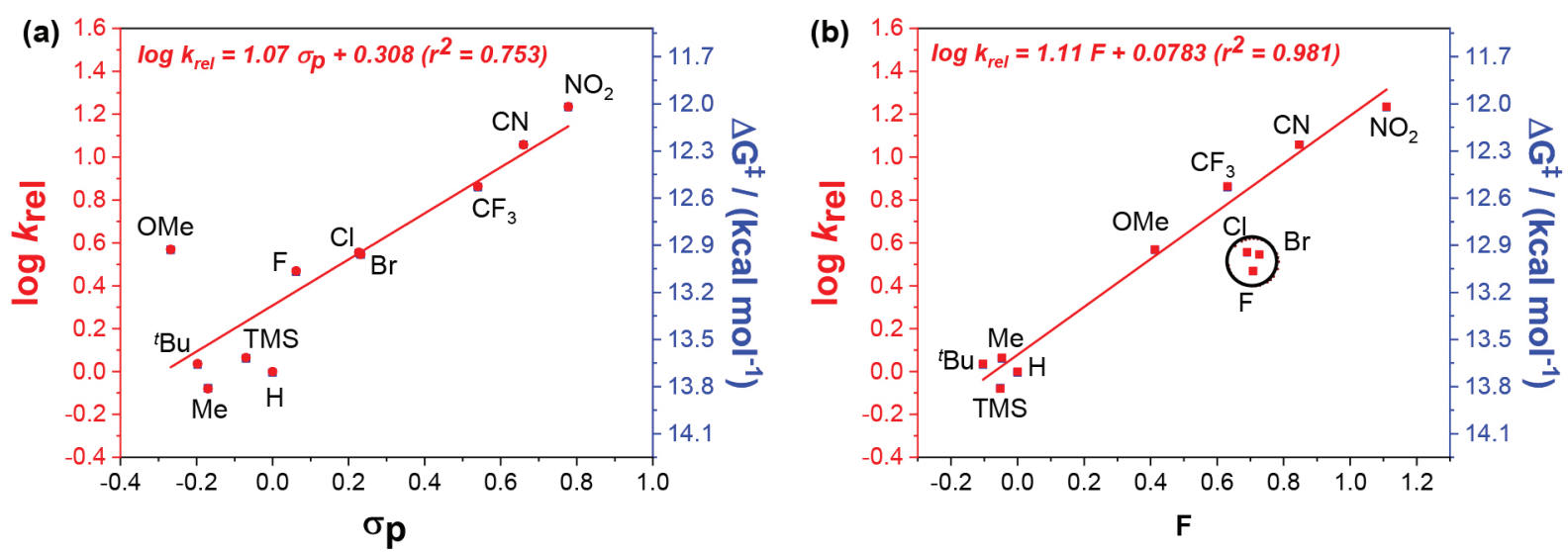

Figure 6. Linear free energy relationships plots with (a) Hammett $\sigma_{\mathrm{p}}$ and (b) Swain and Lupton's field effect (F) constants.

effects on the reaction constants can be evaluated independently by their field $(\mathrm{F})$ and resonance $(\mathrm{R})$ effects. ${ }^{55}$ Figure $6 \mathrm{~b}$ shows that the relative rates $\left(\log \mathrm{k}_{\mathrm{rel}}\right)$ correlate better with the field effect of the substituent (F constants, $\left.r^{2}=0.981\right)$. Conversely, the resonance constant did not correlate in an obvious way with the relative rate constants. The halogens are shown to be outliers. The inclusion of solvent effects and diffuse functions (PCM(DMF)/ UBHandHLYP/6-311++G**//UBHandHLYP/6-311G**) results in the same tendency shown before to reaction barriers (Figure S3, SI section), suggesting that these factors do not significantly influence the results. Considering that the radical at the phenyl moiety is orthogonal to the $\pi$ system, it does not allow resonance to occur effectively, the better correlation with $\mathrm{F}$ is plausible. Thus, the field effect plays a main role in the polar (aka electrostatic, electric field, or field) effect. The stronger is the electronwithdrawing effect of the substituent of the aryl radical, the higher is the reaction rate.

The positive slopes $(\rho)$ suggests the formation of a negative partial charge $\left(\delta^{-}\right)$at its $C_{\alpha}$, being formed in relation to the same atom at the reactant. The atomic charges calculated by $\mathrm{Hu}$, Lu and Yang (HLY) charge fitting method ${ }^{56}$ allows the estimation of the charge accumulation at the atom on the TS and in the reactants. Considering that the charge at the $\mathrm{C}_{\alpha}\left(\mathrm{Q}_{\mathrm{C}_{\alpha}}\right)$, calculated by the HLY method, is $\mathrm{Q}_{\mathrm{C}_{\alpha}}(\mathrm{TS})=-0.756 e$ in the TS, while it is $\mathrm{Q}_{\mathrm{C}_{\alpha}}(\mathrm{enol})=-0.725 e$ at the reactant, the charge accumulation/depletion $(\delta)$ at this carbon in TS can be calculated by $\delta=\mathrm{Q}_{\mathrm{C}_{\alpha}}(\mathrm{TS})-\mathrm{Q}_{\mathrm{C}_{\alpha}}(\mathrm{enol})$, which results in $\delta=-0.031 e$. The negative sign confirms the charge accumulation at $\mathrm{C}_{\alpha}$, in agreement with the value $\left(\delta^{-}\right)$expected by the positive $\rho$ value from the LFER.

The good correlation with field effect can be explained in terms of radical electrophilicity. Strong electronwithdrawing groups, such as $\mathrm{NO}_{2}, \mathrm{CN}$, and $\mathrm{CF}_{3}$, have large dipoles, exerting an electrostatic field $(\mathrm{F})$ which helps to stabilize the accumulation of electron density $\left(\delta^{-}\right)$at the reacting center $C_{\alpha}$. On the other hand, groups that pull electrons, such as alkyl and silyl, tend to have the opposite role.

The arylation of pentan-3-one and cyclohexanone-based enol acetates with $p$ - $\mathrm{NO}_{2}$ substituted phenyl diazonium salt gives yields of 33 and $35 \%$, respectively. ${ }^{14}$ These lower yields compared to the unsubstituted case were attributed to steric demands at $\alpha$-carbon. To evaluate this hypothesis, calculations with alkyl-substituted enol acetate at $\alpha$-carbon at out TS calculations with different alkyl groups bonded to that position were carried out. Taft ${ }^{57-59}$ proposed modification to the Hammett equation to include the influence of steric effect. Later, Charton ${ }^{60-62}$ proposed a new scale where the van der Waals radii of different groups were used as reference. These LFERs were employed to evaluate the steric effect at the desired system.

The DFT calculations show that the exothermicity of the reaction is decreased as bulkier the alkyl group is (Table 2), affecting the barrier height. A bulk group such as ${ }^{i} \mathrm{Bu}$ increased the $\Delta \mathrm{G}^{\ddagger}$ in around $4 \mathrm{kcal} \mathrm{mol}^{-1}$. Cyclic ketones were also evaluated. Cyclohexanone-based enol acetate exhibited similar behavior of $n$-alkyl groups. 1 -Tetralonebased enol acetate showed the lowest $\Delta \mathrm{G}^{\ddagger}$. As this enol acetate has an aromatic ring fused to a cyclohexanone, the resonance effect would stabilize the adduct formed, which could be observed by the lowest exothermicity.

The calculated barrier height showed, excluding the cyclic compounds, poor correlation with the reaction enthalpy $\left(r^{2}=0.442\right.$, Figure $\left.7 a\right)$. It means that exothermicity has an influence on the reaction rate to a small degree, as shown by the slope (0.092) close to zero, and it is not the main factor. As shown previously, the enol acetate acts as the nucleophile, so the plot of barrier height against enol acetate HOMO energy was used to evaluate the polar effect. No correlation was observed, showing that this effect has a low influence on the energy barrier (Figure 7b). 
Table 2. Calculated transition state Gibbs free energy $\left(\Delta \mathrm{G}^{\ddagger}\right)$ and enthalpy $\left(\Delta \mathrm{H}^{\ddagger}\right)$, reaction Gibbs free energy $\left(\Delta \mathrm{G}_{\mathrm{rxn}}\right)$ and enthalpy $\left(\Delta \mathrm{H}_{\mathrm{rxn}}\right)$ at $\mathrm{UBHandHLYP/6}-$ $311 \mathrm{G}^{* *}$ level of theory for $p$-nitrophenyl radical addition to $\alpha$-alkyl enol acetates

\begin{tabular}{|c|c|c|c|c|}
\hline $\mathrm{R}^{2}$ & $\Delta \mathrm{G}^{\ddagger} /\left(\mathrm{kcal} \mathrm{mol}^{-1}\right)$ & $\Delta \mathrm{H}^{\ddagger} /\left(\mathrm{kcal} \mathrm{mol}^{-1}\right)$ & $\Delta \mathrm{G}_{\mathrm{rxn}} /\left(\mathrm{kcal} \mathrm{mol}^{-1}\right)$ & $\Delta \mathrm{H}_{\mathrm{rxn}} /\left(\mathrm{kcal} \mathrm{mol}^{-1}\right)$ \\
\hline $\mathrm{H}$ & 12.0 & 2.2 & -26.3 & -38.6 \\
\hline $\mathrm{Me}$ & 14.0 & 2.1 & -23.7 & -37.1 \\
\hline Et & 14.5 & 2.4 & -23.5 & -37.0 \\
\hline${ }^{n} \operatorname{Pr}$ & 14.6 & 2.4 & -23.4 & -36.9 \\
\hline${ }^{i} \operatorname{Pr}$ & 14.3 & 3.3 & -22.5 & -35.4 \\
\hline${ }^{n} \mathrm{Bu}$ & 14.7 & 2.4 & -23.4 & -36.9 \\
\hline iBu & 15.9 & 4.4 & -22.0 & -34.8 \\
\hline Cyclohexanone & 13.7 & 2.6 & -22.4 & -35.0 \\
\hline 1-Tetralone & 13.1 & 1.6 & -33.1 & -46.2 \\
\hline
\end{tabular}
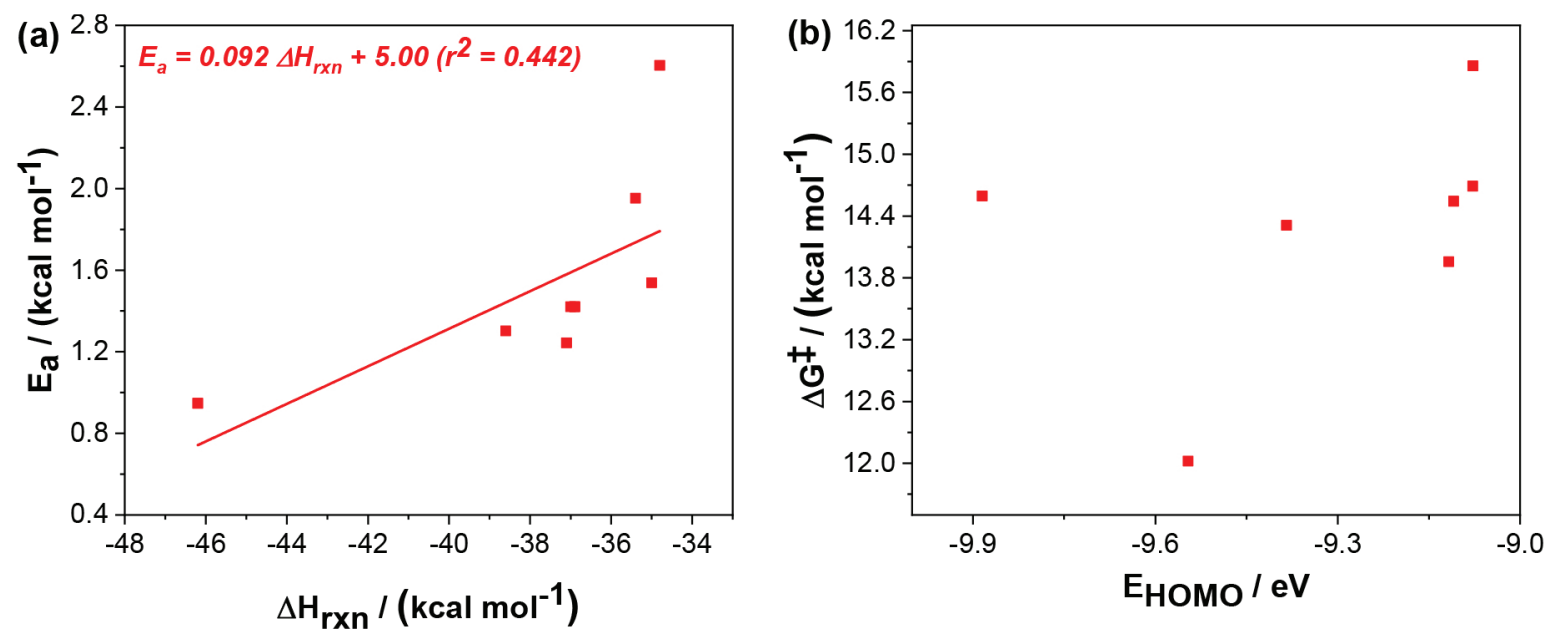

Figure 7. Plots of activation barrier $\left(\mathrm{E}_{\mathrm{a}}\right)$ as a function of the reaction enthalpy $\left(\Delta \mathrm{H}_{\mathrm{rxn}}\right)$ and (b) $\Delta \mathrm{G}^{\ddagger}$ as a function of the $\mathrm{HOMO}$ energy for the addition of $p$-nitrophenyl radical towards $\alpha$-alkyl enol acetates.

The plots of $\log \mathrm{k}_{\mathrm{rel}}$ against steric constants for each showed good correlations: $\mathrm{r}^{2}=0.938$ for Taft (Figure 8a) and $\mathrm{r}^{2}=0.924$ for Charton (Figure 8b) scales (Table S2, SI section). Due to the methyl group is considered the reference for Taft steric analysis, the $\log \mathrm{k}_{\text {rel }}$ for this case was considered as $\log \mathrm{k}_{\mathrm{X}} / \mathrm{k}_{\mathrm{Me}}$, instead of the traditional $\log \mathrm{k}_{\mathrm{X}} / \mathrm{k}_{\mathrm{H}}$. The $\mathrm{r}_{\text {Taft }}=-1.21$ and $\rho_{\text {Charton }}=-2.78$ indicate that steric demands at the $\alpha$-carbon are particularly important in the reaction.

The analysis of structural parameters at transition states can clear what happens in the presence of bulky groups. The approximation distance is reduced up to $0.066 \AA$ but compared to substituted radicals added to acetone-based enol acetate, these parameters are acceptable (see Table S3, SI section, for a complete set of these values). Any other way, the angles of approximation $(\theta)$ deviate around -4 to $-5^{\circ}$ with aliphatic alkyl groups and up to $-6.5^{\circ}$ in case of cyclic enol acetates, getting far from Bürgi-Dunitz trajectory.

Finally, acetophenone-based enol acetates were studied to evaluate how substitution at $\beta$-carbon (Scheme 1, $\mathrm{C}_{\beta}$ ) influences the rate constants. At König and co-workers ${ }^{14}$ work, reactions with three substituted acetophenones $\left(\mathrm{R}^{3}=\mathrm{OMe}, \mathrm{Br}, \mathrm{H}\right)$ were carried out and excellent yields were obtained. In such systems, the substitution had no key effect in the reaction yields. 

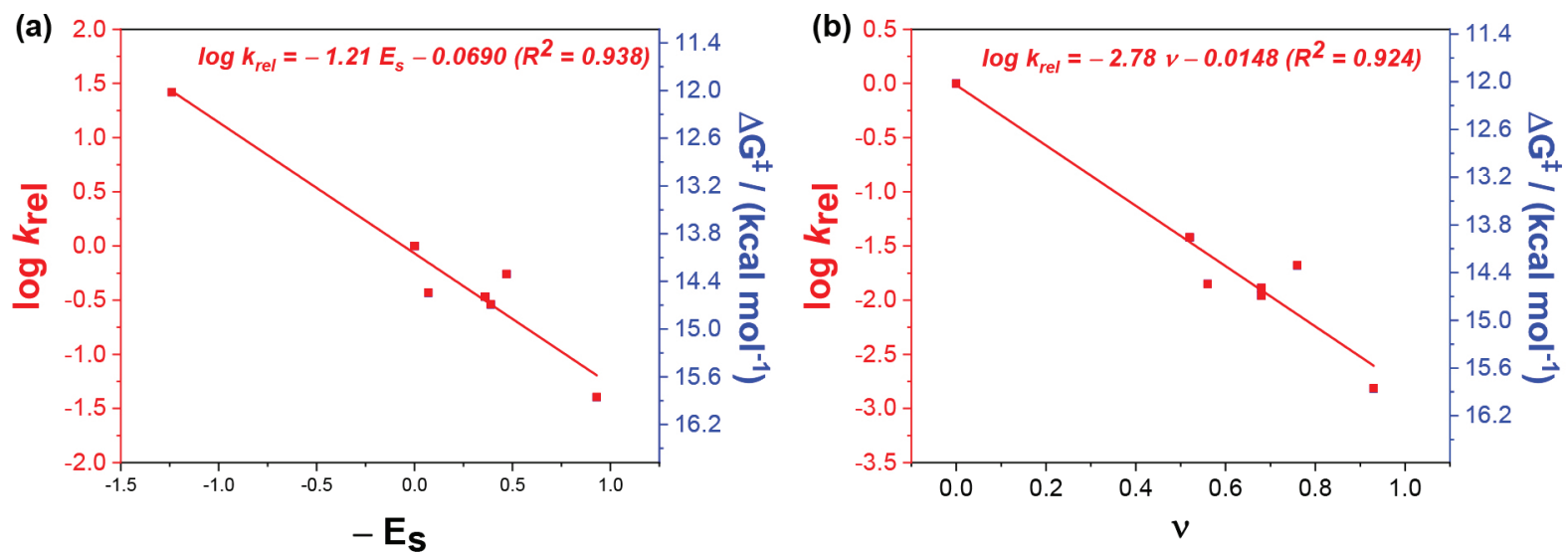

Figure 8. Linear free energy relationships (LFER) plots with (a) Taft $\left(-\mathrm{E}_{\mathrm{s}}\right)$ and (b) Charton constants ( $v$ ) for the addition of $p$-nitrophenyl radical towards $\alpha$-alkyl enol acetates.

The calculated barrier heights (Table S4, SI section) of all the evaluated substituents are close to non-substituted acetophenone. Compared to acetone-based enol acetates, these reactions would be faster with rate constants 10 to 100 times higher. The formation of a new radical species after the addition is stabilized by both phenyl and acetate groups. The plot of the logarithm of the relative rate constants against Hammett constants indicates a good correlation $\left(r^{2}=0.991\right.$, Figure 9$)$, but with a smaller slope $(\rho=-0.649)$, suggesting little influence on the rate. Correlations with field and resonance effects indicate that both contribute to lower barrier heights. Since the radical formed is coplanar to the $\pi$ orbitals, the resonance effect would be an expected factor to influence this system (Figure S4, SI section).

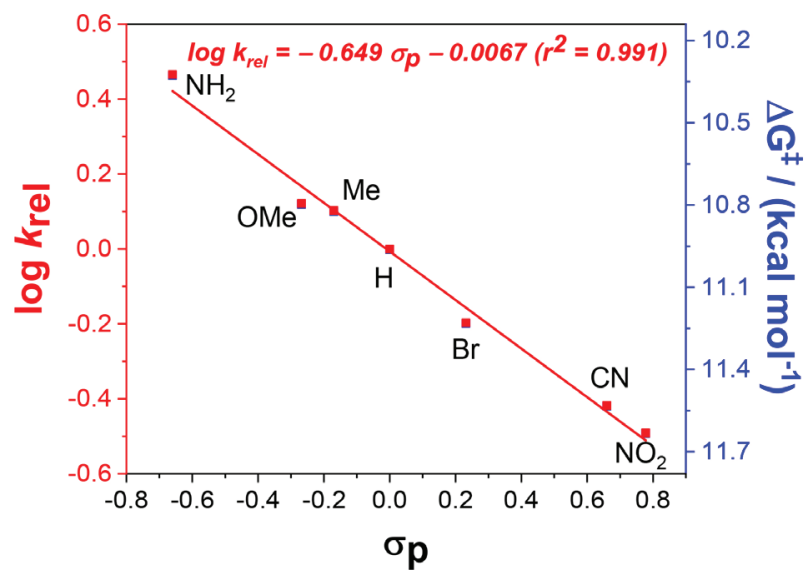

Figure 9. Linear free energy relationship plot against Hammett's $\sigma_{\mathrm{p}}$ constants.

The substitution pattern at the aryl ring of acetophenonebased enol acetate monitors the alkene $\beta$-carbon. The negative slopes of LFER correlations indicate the electron density depletion or accumulation of positive charge at $\beta$-carbon on the TS concerning this atom on the reactants, i.e., $\delta\left(\mathrm{C}_{\beta}\right)=\delta^{+}$. Electron donating groups (EDG) would exhibit higher rates compared to electron withdrawing groups (EWG). The HLY charges were also used for calculating the electron density accumulation/depletion $(\delta)$ at the $\beta$-carbon, i.e., $\left.\delta=\mathrm{Q}_{\mathrm{C} \beta}(\mathrm{TS})-\mathrm{Q}_{\mathrm{C}}(\mathrm{enol})\right)$. Since $\mathrm{Q}_{\mathrm{C \beta}}(\mathrm{TS})=0.329 e$ and $\mathrm{Q}_{\mathrm{C} \beta}(\mathrm{enol})=0.277 e$, this leads to $\delta=+0.052 e$, which confirms the charge depletion at $\mathrm{C}_{\beta}$ at the TS, in agreement with the value $\left(\delta^{+}\right)$expected by the positive $\rho$ value from the LFER shown in Figure 9.

Based on this systematic study, we can summarize important features about electronic demand at both aryl radical and enol acetate that affects the photoredox version of the Meerwein arylation, which may work as guidelines for this reaction. These are: (i) groups that highly pull electronic density by field effect at phenyl radical improve the reaction yields. (ii) electron-donating groups (EDG) directly bonded to the $\beta$-carbon of the enol acetate, will improve the reaction yields and could be interesting to be in synthetic applications when $\alpha$-aryl ketones with oxygenated groups, typical of natural products, are desired; (iii) substitution at $\alpha$-carbon of the enol acetate, such as alkyl groups and cyclic ketones, will decrease the yield.

\section{Conclusions}

We explored the phenyl radical reactivity in additions to enol acetates. Based on the theoretical calculations and supposing that the addition of the phenyl radicals to the enol acetates would be the step responsible for the reactivity, the polar effects are suggested to dominate the influence by the action of the field effect, which is consistent with the early TS. Based on the theoretical Hammett, HLY charges, and NBO analysis, the accumulation of negative charge at the $\mathrm{C}_{\alpha}$ makes the enol acetate the nucleophile of the reaction. The evaluation of the substitutions at the enol acetates showed a strong influence of the substitution at $\mathrm{C}_{\alpha}$ by steric effects 
even reacting with a stronger nucleophile as $p$-nitrophenyl radical. On the other hand, substitution at $C_{\beta}$ did not show a significant influence on the energy barriers. These results suggest that as the reduction of diazonium salts to phenyl radicals is a very fast process, the influence of substituents would not interfere severely at this step and the addition step is critical to determinate the efficiency of the reaction, different from what was proposed in the literature. To confirm this theoretical evidence, kinetic experiments are suggested in the same systems.

\section{Methodology}

The computational calculations were carried out using Gaussian 16 software. ${ }^{63}$ The geometry optimization of reactants and products were performed using BHandHLYP functional ${ }^{64}$ (unrestricted in case of radicals) and 6-311G** basis set. Stationary points were characterized as minima with no negative frequencies analyzing harmonic vibrational frequencies at the same theory level as geometry optimization. TS geometries were calculated at the same level of theory and were confirmed by the presence of only one imaginary frequency. Optimized geometries for all structures in this study are available in the SI section. Molecular orbitals were calculated from the optimized structure using MP2/6-31G** level of theory (the MO energies were obtained in the Hartree-Fock part of the calculation). NBO calculations were performed within its 3.1 version $^{47}$ implemented at Gaussian 03 software. ${ }^{65}$

\section{Supplementary Information}

Supplementary information is available free of charge at http://jbcs.sbq.org.br as PDF file.

\section{Acknowledgments}

To governmental agencies FAPERJ, CNPq, and CAPES.

\section{References}

1. Spielvogel, D. J.; Buchwald, S. L.; J. Am. Chem. Soc. 2002, 124, 3500 .

2. Jin, Y.; Chen, M.; Ge, S.; Hartwig, J. F.; Org. Lett. 2017, 19, 1390.

3. Koch, E.; Takise, R.; Studer, A.; Yamaguchi, J.; Itami, K.; Chem. Commun. 2015, 51, 855.

4. Carril, M.; SanMartin, R.; Churruca, F.; Tellitu, I.; Domínguez, E.; Org. Lett. 2005, 7, 4787.

5. Ghosh, I.; Marzo, L.; Das, A.; Shaikh, R.; König, B.; Acc. Chem. Res. 2016, 49, 1566.
6. Wang, C. S.; Dixneuf, P. H.; Soulé, J. F.; Chem. Rev. 2018, 118 , 7532.

7. Meerwein, H.; Büchner, E.; van Emster, K.; J. Prakt. Chem. 1939, 152, 237.

8. Koelsch, C. F.; Boekelheide, V.; J. Am. Chem. Soc. 1944, 66, 412.

9. Obushak, M. D.; B.Lyakhovych, M.; Ganushchak, M. I.; Tetrahedron Lett. 1998, 39, 9567.

10. Minaev, B. F.; Bondarchuk, S. V.; Russ. J. Appl. Chem. 2009, 82,840 .

11. Bondarchuk, S. V.; Minaev, B. F.; J. Mol. Struct.: THEOCHEM 2010, 952, 1.

12. Schroll, P.; Hari, D. P.; König, B.; ChemistryOpen 2012, 1, 130.

13. Heinrich, M. R.; Chem. - Eur. J. 2009, 15, 820.

14. Hering, T.; Hari, D. P.; König, B.; J. Org. Chem. 2012, 77, 10347.

15. de Souza, A. A. N.; Silva, N. S.; Müller, A. V.; Polo, A. S.; Brocksom, T. J.; de Oliveira, K. T.; J. Org. Chem. 2018, 83, 15077.

16. Baxter, R. D.; Liang, Y.; Hong, X.; Brown, T. A.; Zare, R. N.; Houk, K. N.; Baran, P. S.; Blackmond, D. G.; ACS Cent. Sci. 2015, 1,456 .

17. Zhang, X.; Int. J. Quantum Chem. 2015, 115, 1658.

18. Hofmann, J.; Clark, T.; Heinrich, M. R.; J. Org. Chem. 2016, $81,9785$.

19. Ruiz Espelt, L.; Wiensch, E. M.; Yoon, T. P.; J. Org. Chem. 2013, 78, 4107.

20. Bock, C. R.; Connor, J. A.; Gutierrez, A. R.; Meyer, T. J.; Whitten, D. G.; Sullivan, B. P.; Nagle, J. K.; J. Am. Chem. Soc. 1979, 101, 4815.

21. Baffert, C.; Dumas, S.; Chauvin, J.; Leprête, J. C.; Collomb, M. N.; Deronzier, A.; Phys. Chem. Chem. Phys. 2005, 7, 202.

22. Bevington, J. C.; Ito, T.; Trans. Faraday Soc. 1968, 64, 1329.

23. Migita, T.; Takayama, K.; Abe, Y.; Kosugi, M.; J. Chem. Soc., Perkin Trans. 2 1979, 1137.

24. Scaiano, J. C.; Stewart, L. C.; J. Am. Chem. Soc. 1983, 105, 3609.

25. Preidel, M.; Zellmer, R.; Ber. Bunsenges. Phys. Chem. 1989, 93, 1417.

26. Citterio, A.; Minisci, F.; Vismara, E.; J. Org. Chem. 1982, 47, 81.

27. Lalevée, J.; Allonas, X.; Fouassier, J. P.; J. Phys. Chem. A 2004, $108,4326$.

28. Minisci, F.; Coppa, F.; Fontana, F.; Pianese, G.; Zhao, L.; J. Org. Chem. 1992, 57, 3929.

29. Heinrich, M. R.; Wetzel, A.; Kirschstein, M.; Org. Lett. 2007, 9, 3833.

30. Chen, H.; Fan, W.; Yuan, X. A.; Yu, S.; Nat. Commun. 2019, 10, 4743.

31. Moon, Y.; Park, B.; Kim, I.; Kang, G.; Shin, S.; Kang, D.; Baik, M. H.; Hong, S.; Nat. Commun. 2019, 10, 4117. 
32. Tedder, J. M.; Walton, J. C.; Acc. Chem. Res. 1976, 9, 183.

33. Tedder, J. M.; Walton, J. C.; Adv. Phys. Org. Chem. 1978, 16, 51.

34. Tedder, J. M.; Walton, J. C.; Tetrahedron 1980, 36, 701.

35. Tedder, J. M.; Angew. Chem. 1982, 94, 433.

36. Giese, B.; Angew. Chem., Int. Ed. 1983, 22, 753.

37. Giese, B.; Lachhein, S.; Angew. Chem., Int. Ed. Engl. 1981, 20, 967.

38. Evans, M. G.; Discuss. Faraday Soc. 1947, 2, 271.

39. Evans, M. G.; Gergely, J.; Seaman, E. C.; J. Polym. Sci. 1948, 866.

40. Semenov, N. N.; Some Problems in Chemical Kinetics and Reactivity (Engl. Transl.); Princeton University Press: Princeton, 1958.

41. Alabugin, I. V.; Stereoelectronic Effects: A Bridge Between Structure and Reactivity; $1^{\text {st }}$ ed.; John Wiley \& Sons: Hoboken, NJ, 2016.

42. Fischer, H.; Radom, L.; Angew. Chem., Int. Ed. 2001, 40, 1340.

43. Martinez, O.; Crabtree, K. N.; Gottlieb, C. A.; Stanton, J. F.; McCarthy, M. C.; Angew. Chem., Int. Ed. 2015, 54, 1808.

44. Kyne, S. H.; Schiesser, C. H.; Matsubara, H.; Org. Biomol. Chem. 2011, 9, 3217.

45. Matsubara, H.; Falzon, C. T.; Ryu, I.; Schiesser, C. H.; Org. Biomol. Chem. 2006, 4, 1920.

46. Falzon, C. T.; Ryu, I.; Schiesser, C. H.; Chem. Commun. 2002, $20,2338$.

47. Glendening, E. D.; Reed, A. E.; Carpenter, J. E.; Weinhold, F.; NBO version 3.1, Gaussian Inc., Pittsburgh, 2003.

48. Bürgi, H. B.; Dunitz, J. D.; Lehn, J. M.; Wipff, G.; Tetrahedron 1974, 30, 1563.

49. Hammond, G. S.; J. Am. Chem. Soc. 1955, 77, 334.

50. Evans, M. G.; Polanyi, M.; Trans. Faraday Soc. 1936, 32, 1333.

51. Lalevée, J.; Allonas, X.; Genet, S.; Fouassier, J.-P.; J. Am. Chem. Soc. 2003, 125, 9377.

52. Klopman, G.; J. Am. Chem. Soc. 1968, 90, 223.

53. Salem, L.; J. Am. Chem. Soc. 1968, 90, 543.

54. Creary, X.; Mehrsheikh-Mohammadi, M. E.; Mcdonald, S.; J. Org. Chem. 1987, 52, 3254.
55. Swain, C. G.; Lupton, E. C.; J. Am. Chem. Soc. 1968, 90, 4328.

56. Hu, H.; Lu, Z.; Yang, W.; J. Chem. Theory Comput. 2007, 3, 1004.

57. Taft, R. W.; J. Am. Chem. Soc. 1953, 75, 4538.

58. Taft, R. W.; J. Am. Chem. Soc. 1952, 74, 2729.

59. Taft, R. W.; J. Am. Chem. Soc. 1952, 74, 3120.

60. Charton, M.; J. Am. Chem. Soc. 1975, 97, 1552.

61. Charton, M.; J. Am. Chem. Soc. 1975, 97, 3691.

62. Charton, M.; J. Org. Chem. 1976, 41, 2217.

63. Frisch, M. J.; Trucks, G. W.; Schlegel, H. B.; Scuseria, G. E.; Robb, M. A.; Cheeseman, J. R.; Scalmani, G.; Barone, V.; Petersson, G. A.; Nakatsuji, H.; Li, X.; Caricato, M.; Marenich, A. V.; Bloino, J.; Janesko, B. G.; Gomperts, R.; Mennucci, B.; Hratchian, H. P.; Ortiz, J. V.; Izmaylov, A. F.; Sonnenberg, J. L.; Williams; Ding, F.; Lipparini, F.; Egidi, F.; Goings, J.; Peng, B.; Petrone, A.; Henderson, T.; Ranasinghe, D.; Zakrzewski, V. G.; Gao, J.; Rega, N.; Zheng, G.; Liang, W.; Hada, M.; Ehara, M.; Toyota, K.; Fukuda, R.; Hasegawa, J.; Ishida, M.; Nakajima, T.; Honda, Y.; Kitao, O.; Nakai, H.; Vreven, T.; Throssell, K.; Montgomery Jr., J. A.; Peralta, J. E.; Ogliaro, F.; Bearpark, M. J.; Heyd, J. J.; Brothers, E. N.; Kudin, K. N.; Staroverov, V. N.; Keith, T. A.; Kobayashi, R.; Normand, J.; Raghavachari, K.; Rendell, A. P.; Burant, J. C.; Iyengar, S. S.; Tomasi, J.; Cossi, M.; Millam, J. M.; Klene, M.; Adamo, C.; Cammi, R.; Ochterski, J. W.; Martin, R. L.; Morokuma, K.; Farkas, O.; Foresman, J. B.; Fox, D. J.; Gaussian 16, Revision C.01; Gaussian, Inc., Wallingford CT, 2016.

64. Becke, A. D.; J. Chem. Phys. 1993, 98, 1372.

65. Frisch, M. J.; Trucks, G. W.; Schlegel, H. B.; Scuseria, G. E.; Robb, M. A.; Cheeseman, J. R.; Montgomery Jr., J. A.; Vreven, T.; Kudin, K. N.; Burant, J. C.; Millam, J. M.; Iyengar, S. S.; Tomasi, J.; Barone, V.; Mennucci, B.; Cossi, M.; Scalmani, G.; R, J. A.; Gaussian 03, Revision C.02; Gaussian, Inc., Wallingford CT, 2004.

Submitted: June 10, 2020 Published online: September 21, 2020 